\title{
MİDHAT PAŞA HAKKINDA YENI YAYINLAR VE GÖRÜŞLER
}

Prof. Dr. Bekir Sitkı BAYKAL

Üstad İsmail Hakkı Uzunçarşılı, 1946 yılında yayınladığı Midhat ve Rüsstü Paşaların Tevkiflerine Dair Vesikalar ve 1950 de çıardığı Midhat Paşa ve Taif Mahkûmları adlı kitaplardan sonra șimdi de Midhat Paşa ve Yıldız Mahkemesi başlığını taşıyan cildi yayım alanına koymakla bu konu üzerindeki çalışmalarını tamamlamış görünmektedir. Böylece, her ne kadar üzerlerinde cilt numaraları yoksa da, gerçekte birbirini tamamlayan üç ciltlik bir eser meydana gelmiş bulunmaktadır. Burada bu eserin her üç cildi hakkında kısaca bilgi vereceğiz. Amacımız, eseri tanıtmak ve bu vesile ile bâzı düşüncelerimizi söylemekten ibarettir.

I

\section{Midhat ve Rüştü Paşalarm Tevkiflerine Dair Vesikalar}

(Türk Tarih Kurumu yayınları, VII. Seri. No. 13, Ankara 1946) adlı kitap, bu eserin kronoloji bakımından birinci cildini teşkil etmektedir. Kitap 179 sahife metinle, kişi ve yer adları ayn ayn olmak üzere iki endeks ve sonuna eklenen 15 levha içinde çeşitli vesika fotokopileri ile Midhat ve Rüştü Paşalara ve bu Paşaların sorgularını yapan Savcı Abdülâtif Bey ile Başsaveı Lebib Efendiye ait beş fotoğraftan ibarettir.

179 sahifelik metin iki ana bölüme ayrılmış olup bunun 100 sahifesi Midhat Paşa ile, geri kalan kısmı ise Rüştü Paşa ile ilgili bilgi ve belgeleri kapsamaktadır. Birinci bölümde yazar, Midhat Paşanın Avrupada uzunca süren bir sürgün hayatından sonra yurda dönüşünü, birbiri ardından Suriye ve Aydın valiliklerine tâyin edilişini kısaca hikâye etmekte, müteâkiben de Yıldız sarayında Padişah Sultan Abdülhamid'in emri ile, Sultan Abdülaziz'in ölümünden suçlu tutulan kimseler meyanında Midhat Paşanın da tevkif edilmesi kararının nasıl verildiğini ve bu kararın ne şekilde uygulama alanına konduğunu anlatmaktadır. Uygulama sırasında Midhat Paşanın Vali bulunduğu İzmir'de cereyan 
eden olaylar, İstanbul'dan surf bu işe memur edilerek gönderilmiş olan Yaver Binbaşı Hüsnü Beyin faaliyetleri, Midhat Paşanın Fransa Konsoloshanesine sığınması, bu olaydan çıkan sorunlar ve nihayet Midhat Paşanın, Padişah ve hükümetin adaletine ve mahkemenin alenî olacağına dair kendisine verilen teminata güvenerek, hükümete teslim olması hadiseleri oldukça etraflı olarak hikâye edilmektedir. Bundan sonra, İstanbul vapuru ile başkente doğru yola çıkarılan Midhat Paşanın, o vaktin Adliye Nâzırı Ahmet Cevdet Paşa başkanlığında özel olarak İzmir'e gelmiş olan bir heyet tarafından sorgusu başlamaktadır. Tekrar tekrar yapılan bu sorguların aynen verilen tutanaklarından Midhat Paşanın, Sultan Abdülaziz'in son zamanlarında memleketin genel durumuna, Padişahın davranışları ve aleyhindeki cereyanlara, ayrıca da kendisinin İzmir'de tevkifine dair etraflı ve dikkate değer bilgiler veren ifadeleri okunmaktadır. Bölümün sonunda sıra ile, Midhat Paşanın tevkifi hakkında Yaver Hüsnü Beyin ve İzmir Kumandanı Hilmi Paşanın raporları, bâzı yabancı gazetelerin bu konu ile ilgili olarak yayınladıkları yazılar ve nihayet Sorgu heyetinin tertip ettiği fezleke yer almaktadır. (s. 63-100).

İkinci bölümde, Sultan Abdülaziz'in tahttan indirilişi sırasında Sadrâzamlık mevkiini işgal etmekte olan Mehmet Rüştü Paşa ele alınmaktadır. Bu bölümde de esas itibariyle aynı usul tâkip olunmuştur. Yalnız fazla olarak Mehmet Rüştü Paşanın karakteri hakkında, mevcut kaynaklara dayanan etraflı bilgi verilmektedir.

Yıldız sarayında, Sultan Abdülaziz'in tahttan indirilişi ve ölümü ile ilgili kişilerin tevkif edilmelerine karar verildiği sıralarda Mehmet Rüştü Paşa Manisa'da bulunuyordu ve ağırea hasta idi. Buna rağmen kendisi İzmir'e kadar getirilmiş, sorgusu yapılmış, fakat sonra hekim raporlarına uyularak yargılanmasından şimdilik kaydiyle vazgeçilip Manisa'ya geri gönderilmiştir. Beş defa yapılan sorgusuna ait tutanak ile neticede kaleme alınan fezleke de kitabın sonuna konmuş bulunmaktadir.

Eserin metin kısmının son iki sahifesi, Midhat ve Mehmet Rüştü Paşaların tevkif ve sorguya çekilmelerinde rol almış olan belli başlı kişilerin, yâni Ahmet Cevdet Paşa, Hüseyin Hüsnü Bey (Paşa), Abdüllâtif Bey, Lebib Efendi ve hekim İsak Beyin kısa hal tercümelerine ayrılmıștır.

Yazar, eserde meveut vesikalar dışındaki bilgileri, Midhat ve Rüştü Paşalara dair bilinen kaynaklara dayanarak özet halinde vermek- 
tedir. Vesikaların kendilerini ise bâzen özetlemiş, bâzen de aynen koymuş, fakat bunları yorumlamaktan ve bunlara dayanarak her hangi bir hükme varmaktan titizlikle kaçınmıştır. Hükümler vermek işini, ayni vesikaları inceleyecek olanlara bırakmağı tercih etmiştir. Önsözünde kendisi aynen şöyle demektedir:

"Bu eseri yazarken sağa veya sola kapılmadan, hissiyâta tâbi” olmayarak vesikaları kısaca hulâsa etmekle iktifa ettim ve bu hususta esaslı hükümleri tarihin bu kısmını tahlil edeceklere bıraktım. Suretlerini koyduğum vesikaların mütalâası, o tarihlerdeki havayı, riyakârlıkları, jurnalcılık faaliyetlerini ve bâzı ricâlin karakterlerini göstermek itibariyle de mucib-i ibrettir."

Gerçekte yazar, böyle çekingen ve son derece ihtiyath davranmak ihtiyacını duymaktadır. Çünkü meselenin iç yüzünü deşecek vesikalar henüz elinde yoktur ve meselenin tümü hakkında tam bir tereddüt içindedir. Şüphesiz ki bu durum içinde bir ilim adamının başka türlü hareket etmesi düşünülemez.

II

Aynı yazar tarafından yayınlanan "Midhat Paşa ve Taif Mahkûmları (Türk Tarih Kurumu Yayınları VII. Seri . No, 18. Ankara 1950), kronoloji bakımından Midhat Paşa hakkındaki eserin üçüncü cildini teşkil etmektedir. 219 sahife tutan metin kısmı sekiz bölüme ayrılmıştır. Başta Midhat Paşa ve kendisiyle birlikte hüküm giyen arkadaşlarının, Sultan Abdülaziz'in kaatilleri olarak suçlandırılmaları için girişilen faaliyetlere kısaca temas edildikten sonra bunların Taif'e nasıl gönderildikleri ve buradaki çile dolu sürgün hayatları tasvir olunmaktadır. Midhat ve Damat Mahmud Celâleddin Paşaların Taif zindanında şehit edilmeleri olayına özel bir bölüm ayrılmıştır. (Bl. IV). Facianın hazırlanması, sahneye konuşu ve bu arada bütün olup bitenler ayrıntılı bir şekilde bu bölümde anlatılmaktadır. Yine ayrı bir bölümde (Bl. VI) Taif mahkûmlarından 12 kişinin (Midhat Paşa, Damad Mahmud Celâleddin Paşa, Damad Nuri Paşa, Hasan Hayrullah Efendi, Mâbeyinci Fahri Bey, Seyyit Ahmet Bey, İzzet Bey, Necip Bey, Namık Paşa zade Ali Bey, Pehlivan Mustafa, Hacı Mehmed ve Cezayirli Mustafa) kısa hâl tercümeleri verilmektedir. Son bölümde ise bâzı önemli vesiklar ve mektuplar yer almaktadır. 
Bu kitap, şimdiye kadar bilinen kaynaklara ilâve olarak, baştan başa arşiv malzemesine dayanmaktadır. Bu itibarla, hükümlülerin İstanbul'dan hareketlerinden itibaren kendileri ile ilgili bütün resmî işlemler, hareket, yolculuk, Taif'e varış, karşılanış, oradaki mahbes hayatı, kendilerinin ve muhafazalarına memur edilen kimselerin bütün davranışları ve faaliyetleri resmî vesikalara dayanılarak etraflı bir şekilde tasvir olunmaktadır.Sultan Andülhamid'in Midhat Paşadan ne kadar kuşkulandiğı, Damat Mahmut Celaleddin Paşadan ne kadar nefret ettiği, bunlar hayatta kaldıkça kuruntu ve vehimler içinde rahatının kaçtığı gayet açı bir şekilde ortaya konmaktadır. Bu sebeplerle her iki Paşanın da bir an evvel bu dünyadan göçmeleri için Padişahın giriştiği faaliyet ve tertipler, zehirletme teşebbüsleri v. b., nihayet gecenin birinde zindandaki hücrelerinde iki Paşanın aynı anda cellatların elinde boğularak can vermeleri ve bunlarla ilgili hadiseler gayet canl ve son derece ibret verici bir şekilde gözlerimizin önüne serilmektedir.

Sahife 150-219 da yer alan vesikaların bir kısmını mahkûmlar ile ilgili resmî muhabereler, diğer kısmını ise mahkûmların aileleri ve yakınları ile yaptıkları yazışmalar teşkil etmektedir. Bu vesile ile mahkûmların gizli yollardan nasıl ve kimlerin aracılığı ile muhabere ettikleri de açılanmaktadır. Birçok noktalarda olduğu gibi, bu hususta verilen bilgiler de, genel olarak, Midhat Paşanın oğlu Ali Haydar Midhat tarafindan yayınlanan Tabsıra-i İbret ve Mir'at-ı Hayret başlıklı iki ciltlik eserdeki mâlumata uygun düşmekte ve şüphesiz ki bunu aşmaktadır. Yazışmalar arasında Midhat Paşanın ailesi ve yakınlarına gönderdiği mektuplarla bunların cevaplarını teşkil eden dokuz mektup sureti bulunmaktadır. Zevcesine yazdığı mektuplarda Midhat Paşa, yer yer zindandaki hayatı hakkında son derece ilginç bilgiler vermektedir. Ayrıca Damat Mahmut Celâleddin Paşa, eski Şeyhülislâm Hasan Hayrullah Efendi, Sultan Abdülaziz'in ikinci Mâbeyincisi Fahri Bey, Seyyid Bey ve mahkûmlardan diğer bâzılaarının mektupları da bu meyanda yer almaktadır. Böylece mektupların sayısı yirmi üçü bulmaktadır. Bu vesikalar dikkatle okunduğu zaman yalnız mahkûmların zindan hayatında çektikleri 1ztırablar değil, fakat aynı zamanda o devrin memur ve devlet ricalinin zihniyet ve tutumları gözlerimizin önünde canlanır, çok kere içimiz sızlar ve tüylerimiz ürperir.

Kitabın sonuna şahıs ve yer adlarına ait olmak üzere iki endeks konmuştur ki bunlar, eserin kullanılışını kolaylaştırmaları bakımından 
elbette faydadan hali değildir. Arkasından gelen beş fotoğraftan biri Midhat Paşaya, biri Damat Mahmut Celaleddin Paşaya, ikisi Damat Nuri Paşaya ve sonuncusu da Hicaz Vali ve Kumandanı Osman Nuri Paşaya ait bulunmaktadır. Ayrıca yazar, özel önemde saydığı yirmi sekiz tane arşiv vesikasının fotolopisini de kitabın sonuna eklemiş bulunmaktadir.

\section{III}

Üstad Uzunçarşılı'nın Midhat Paşa ile ilgili yayınlarının en çok ilgi çekici kısmı, şüphesiz ki son olarak yayınlandığı Midhat Paşa ve Yıldız Mahkemesi (Türk Tarih Kurumu Yayınları, VII. Seri. No. 53. Ankara 1967) başlığını taşıyan cilttir. Ayrıca yazarın, aslında eserinin ikinci cildi olan bu kısmın yayınlanması için uzun yıllar beklemesinin nedenini de buradan öğrenmekteyiz: Yazar, Sultan Abdülaziz'in ölümü meselesinde bugüne kadar tereddütler içinde kalmış, yâni bu ölümün bir intihar mı yoksa katil suretiyle mi vukubulduğu hususunda her türlü şüpheden arınmış kesin bir hükme varamamış bulunuyordu. Kendisinden önce aynı sorunu ele alan araştırmacılardan Abdurrahman Şeref ve İbnülemin Mahmut Kemal (İnal) Beyler de aynı durumda idiler, yâni bunlar da kesin bir sonuca varamamışlardı.Buna karşılık Vakanüvis Lütfi Efendi, ölümün katil suretiyle vuku'bulduğu kanısına meyil göstermiş bulunuyordu. Uzunçarşılı da eskiden mütalâa ettiği eser ve vesikaların etkisi altında kalarak yıllarca daha ziyade bir katil fiili ile karşı karşıya bulunulduğu sanısını beslemiş, fakat bunu bir hüküm olarak destekliyecek kesin deliller elde edemediğinden ifade edecek zamanın henüz gelmemiş olduğu kanaatını taşımıştı. Ancak, son yıllarda Yıldız sarayı arşivinin araştırıcılara açılması, meselenin bütününe bir ışı tutmuştur. Gerçekten de Yıldız evrakı arasında Sultan Abdülhamit tarafından kendi şahsı için hazırlatılmış mükemmel bir Yıldız Mahkemesi dosyası ele geçmiştir. Aynı dâvanın Adliye arşivinde bulunması gereken asıl dosyası daha önce yanmış bulunduğundan, belki de ebediyete kadar karanlıkta kalmağa mahkûm görünen bu "intihar mi, yoksa katil mi?" meselesinde yazar, Yıldız evrakı arasındaki bu dosyayı mütalâa etmekle kesin bir hükme varmak imkânını bulmuştur. Bunları inceledikten sonra Abdülaziz'in intihar ettiğine artık hiç bir şüphesi kalmayınca da önemli eserini tamamlamak için bu son cildi yayınlamıştır. 
Midhat Paşa ve Yıldız Mahkemesi, 362 sahifelik metin, 19 sahifelik endeks ve 58 sahife vesika fotokopilerinden teşekkül etmektedir. Ayrıca kısa bir de bibliyografya eklenmiştir. Önsöz'den sonra başlayan metin yirmi bir bölüme ayrılmış bulunmaktadır. İlk altı bölüm, Sultan Abdülaziz'in hükümdarlık devri, son zamanlarında İstanbul'un durumu, çeşitli cereyanlar, tahttan indirilmesi ile ilgili faaliyetler ve nihayet bu plânın uygulanması, hal'iden ölümüne kadar geçen olaylar, ölümü, eğer ölmeseydi sağ bırakılır mıydı? gibi konuların işlenmesine tahsis olunmuştur. Kısaca Sultan Murad'dan bahs edildikten sonra Abdülhamid'in ilk saltanat yıllarına ve Sultan Abdülaziz'in ölümünün hemen arkasından resmen açıklanmış olan intiharı olayının şüpheli bir hale sokulması, ölümün katil suretiyle vuku'bulduğu inancının yayılması ve onun tahttan indirilişinde rol almış olan kimselerin aramı bulunması meseleleri ele alınmaktadır. Müteakiben tahkikat, suçluların yakalanması, dâvanın safhaları ile sonucu anlatılmaktadır. Son bölümde de Yıldız mahkemesi Başkanı Ali Sururî Efendi ile ikinci Başkan Hristo Forides Efendinin, aynı mahkeme üyeleri Hüseyin Hamit ve Mehmet Emin Beylerin, Hacı Emin, Gadban ve Emrullah Efendilerin, Saveı Abdüllâtif ve Saveı yardımcısı Mehmet Raşit Beylerin, Mustantık Fıkdıklı'lı Mehmet Nazmi ve Hüseyin Sıtkı Efendilerin kısa hâl tercümeleri verilmektedir. Bunları, "Heyet-i ithamiye" Reis ve azâlarının keza kısa hâl tercümeleri takip etmektedir. Sankların sorguları ve yargılanmaları sıralarında Sultan Abdülhamid'in âlet olarak kullandığı şahıslar sıfatiyle Mahmut Nedim, Ahmet Cevdet ve Mahmut Celâleddin Paşalarla Mâbeyinci Ragıb Beyin ve nihayet muhakeme sırasında sanıkların avukatlıklarını yapmak üzere sarayca tâyin olunan beş zatın kısa biyografilerine yer verilmiştir.

Eser, genel olarak şimdiye kadar kullanılmamış olan arşiv malzemesine dayanmaktadır ve sırf bu bakımdan bile tamamiyle orijinal bir mahiyet arz etmektedir. Kitabın mütalâasından anlaşıldığına göre Sultan Abdülhamid, amcası Sultan Abdülaziz'in başka kimseler tarafindan katl edilmiş olduğuna kendisi de inanmamaktadır, fakat böyle bir dâvayı tertip ile ve tamamiyle sun'î olarak vücuda getirmiştir. Padişahı böyle davranmağa sevk eden âmiller ve onun bundan elde etmek istediği başlıca gayeler şu şekilde sıralanabilir:

1- Sultan III. Selim'in tahttan indirilip feci bir surette öldürülmesinden beri geçen yetmiş yıldır unutulmuş olan Padişah hal'i ve katli 
olayı, Sultan Abdülaziz ile Sultan V. Murad'ın birbiri arkasından tahttan indirilmeleri ile birden bire tazelenmiștir. Bu hâl, kendisinin de aynı akıbete uğraması ihtimalini kuvvetlendirmekte ve bu sebeple Sultan Abdülhamidi daimi bir kuruntu ve korku içinde yaşatmakta idi. İşte böyle bir ruh haleti içinde idi ki Padişah, kendisine karşı bu gibi bir hareketin tekrarlanmasına meydan vermemek amacı ile, son hal'i ve ölüm suçlularını âleme ibret olacak ve her kesi sindirecek bir şekilde şiddetli cezalara çarptırmak lüzumunu duymakta idi.

2- Sultan V. Murad'ın cülusundan üç ay gibi kısa bir süre sonra tahttan indirilmesinin sebebi, o talihsiz hükümdarın mübtela olduğu akıl hastalığı idi. Tedavi edilmesi imkânsız nevi'den olan aynı hastalık hâla devam etmekte olmasına rağmen Sultan Murad'ın bir takım taraftarları vardı ki bunlar gün geçtikçe Sultan Abdülhamid'in idaresinden daha ziyade memnunsuzluk duymakta ve bu sebeple Sultan Murad'ı yeniden tahta geçirmek için faaliyet göstermekte idiler. İşte Abdülhamid, vehim ve endişe içinde büyük bir dikkatle tâkip ettiği bu proMurad faaliyetlere kesin surette bir son vermek azmindedir ve bu gaye ile tasnî' ederek yaratmış olduğu dâvaya Sultan Murad ile yakınlarını da katmak ve bunlan sorumlu bir duruma düşürerek, ağabeyisinin kendisi için teşkil ettiği tehlikeyi büsbütün ortadan kaldırmak kararındadir.

3- Sultan Abdülaziz'i ve Sultan V. Murad'i tahttan indirmekte fiilî rol oynayan devlet erkânının büyük bir kısmı hâla hayatta idiler. Gerçi Sultan Abdülhamid, 1877 - 1878 Osmanlı - Rus savaşında uğranılan yenilgiden faydalanarak bunların bâzılarını zararsız hale getirmiș bulunuyordu. Bu meyanda Sultan Abdülaziz'in hal'inde Harbiye kumandanı olan ve bu okul öğrencilerini silâhlandırarak Dolmabahçe sarayını kuşatmış bulunan Süleyman Paşayı Bağdad'a sürmüştü. Aynı şekilde, Sultan Abdülaziz'in taht'tan indirilmesinin şer'an câiz olduğuna dair fetva vermiş olan devrin Şeyhülislâmı Hasan Hayrullah Efendiyi de Hicaz 'a nefy etmişti. Fakat saltanatı için en tehlikeli adam olarak saydığı Midhat Paşa ile Mehmed Rüştü ve Mahmud Celâleddin Paşalar halâ bir heyula gibi ortada dolaşıyorlardı. İşte bunlar ayakta durdukça rahat edemeyen Padişah, kendilerini kaatil ve câni duruma düşürmek suretiyle onlardan kesin olarak kurtulmak için, amcası Sultan Abdülaziz'in ölümü olayını elverişli bir vesile saymıştır. Bu firsattan faydalanılarak onlar câni ve kaatil damgasını yemeli ve böylece ebediyen mahv edilmeli idiler. 
Üç noktada özetlediğimiz bu sebeplerden dolayı Sultan Abdülhamid, tamamiyle sun'î olarak bir Sultan Aziz dâvası yaratmak suretiyle asıl amacına ulaşmak istemiștir. Yıldız Mahkemesinde gördürdüğü bu düzmece dâva sırasında vehimli Padişah, gayesi uğrunda Makyavelist ölçüleri de aşan davranışlarla her türlü vasıtaya baş vurmakta bir sakınca görmemiştir. Yurdun dört bucağından yakapaça toparlatılıp getirttiği sanıkları önce birer birer önüne alarak sorular sormuş ve onlardan kendi isteğine uygun cevaplar vermelerini talep etmiştir. Sözde suçlarım itiraf etmemekte direnenlere fena halde hiddetlenmiş ve bunları türlü türlü işkencelere tâbi tutmuştur. Uygulanan işkenceleri bizzat idare etmekte, hatta çoğunu kendi eliyle icra eylemektedir. Bu maksatla sadece basit birkaç zavallıyı veya şahsî kölelerini değil, fakat yüksek mevkiler işgal etmekte olan devlet erkânından bâzılarını da âlet olarak kullanmaktadır. İşine yarıyabilecek zayıf karakterli insanları seçmekte eşsiz bir maharet göstermektedir. Düzmece dâvayı kurabilmek için bu adamlar ve Padişah baş başa verip bir plân tertip etmişlerdir. Buna göre Sultan Abdülaziz'in ölümü şöyle cereyan etmiş olmah idi: Sultan V. Murat ile annesi, Sultan Abdülaziz'in öldürülmesi için emir vermişlerdi ve bu irade, Mâbeyinci Seyyid Bey aracılığı ile Damat Mahmud ve Damat Nuri Paşalara iletilmişti. Bunun üzerine Damat Paşalar, Sultan Murad'ın adamlarından Pehlivan Mustafa, Hacı Mehmet ve Cezayirli Mustafa adında üç kişiyi eski Padişahın öldürülmesine memur etmişlerdi. Aynı zamanda Sultan Abdülaziz'in yanında bırakılmış olan ikinci Mâbeyincisi Fahri Beye bu yolda tâlimat vermişlerdi. Böylece Fahri Bey bir sabah erkenden bu üç kişiyi Fer'iyye dairesine gizlice almış, Pehlivan Mustafa'ya beyaz sedef saplı bir çakı vererek yine kimse görmeden kurbanlık Abdülaziz'in odasına sokarak kendisi arkasından sıkıca onu kavramış, Hacı Mehmet ile Cezayir'li Mustafa, dizlerine oturmuş ve Pehlivan Mustafa da mâhud çakı ile eski hükümdarın kollarını kesmiş idi. İçerde cinayet işlenirken iki subay kılıçlarını çekmiş oldukları halde oda kapısının önünde nöbet tutmuşlar, dört Haremağası da bunlara nezâret etmişlerdi. İşte sanıklarm bu yolda ifade vermeleri isteniyordu. "Matlûb-ı şahâneye" uygun söylemiyenler şiddetli işkencelere tâbi tutuluyorlardı.

Bütün bu tertipler ve tasni'ler sayesinde Sultan Abdülhamid, cehennemî bir işkence sistemine dayanamayıp nihayet kendisine öğretildiği şekilde "Sultan Abdülaziz'i falan ve filanın da yardımiyle ben öldürdüm" diye güya itirafta bulunan Pehlivan Mustafa adında cahil 
ve saf bir zavallıyı bulabilmiș ve bütün dâvasını bu biçârenin ifadesi üzerine bina etmeğe muvaffak olmuștur. Doğrudan doğruya gözlerinin önünde ve şahsî denetimi altında yürüttüğü mahkeme bir adalet cihazı olmaktan çok bir sahne oyununu andırmaktadır. Yargıçlar hükümlerini, efendilerinin istekleri istikametinde peşin olarak vermiş bulunmaktadırlar. Zamanın Adliye Nâzırı bulunan Ahmet Cevdet Paşa çapında bir insan bile bu tüyler ürpertici trajedide Padişahın körü körüne bir âleti olarak karşımızda durmaktadır. Hakimler olșun, Padişahın diğer yardakçıları olsun, sanıklara karşı, haklı veya haksız yere eskiden beri içlerinde birikmiş kin ve intikam duygularına kapılıp sürüklenen kimselerdir. Örneğin, mahkemenin Başkanı Sururî Efendi-ki emellerine yaptığı hizmetlere mükâfat olarak Padișah, ölümünden sonra ona bir türbe yaptırmıștır- uygunsuz davranıșları yüzünden Tuna valisi Midhat Paşa tarafindan vilayetinden kovulmuş bir yargıçtır. Bunun gibi daha birçoklarının içinde sanıklara karşı garez kaynamaktadır. Hâsılı yaranmak, göze girerek kolay tarafindan yükselmek ve bir mevki kapmak yarıșı, dalkavukluk ve şahsî menfaat ihtirası gözleri karartmış, kulakları sağır kılmıştır. Kafalar durmuș, mantık işlemez olmuştur. Aklı başında sanıkların vekarla yaptıkları savunmalar, ortaya koydukları aklî ve kanunî deliller asla dikkate alınmamıştır. Hatta daha da ileri gidilerek, resmî sıfat ve mevkiin sağladığı yetki ve otorite ile, sanıklar "zülf-i yâre" dokunacak gibi olunca, derhal sözleri kesilmiş, konuşmaktan men" olunmuşlardır. Mahkemenin alenî olacağı ilan ve temin edildiği halde alınan son derece sıkı tedbirlerle gayet sınırlı sayıda dinleyici içeriye bırakılmıştır. Böyle bir hava içinde yürütülen yargılamanın sonucunu önceden kestirmek hiç de güç değildir: Cinayetle itham olunarak mahkemeye sevk olunan on bir sanıktan yalnız ikisi onar yıl ağır hapis ve geri kalan dokuzu da idam cezalarına çarptırılmışlardır. Bununla beraber Padişah, bu kararları, temyiz mahkemesi tarafından da tasdik edilmiş olmalarına rağmen infaz etmek cesaretini gösterememiştir. Temyizden sonra önce Meclis-i vükelâ'da, sonra da eski Sadrâzamlar, Nâzırlar, Müșirler ve Feriklerden olușan yirmi beș kișilik özel bir mecliste aynı kararları uzun uzun tetkik ettirmiştir. Ayrıca ulemâdan mürekkep bir meclis daha toplayarak bilhassa Sultan Murad ile validesinin "âmir-i mücbir" sayılıp sayılamıyacağı meselesini inceletmiştir. Son olarak toplanan özel mecliste meseleyi saatlerce inceleyen üyelerin çoğu cezaların aynen infaz edilmesine, azınlıkta kalan diğer kısmı ise cezaların hafifletilmesine taraftar olmuşlar ve oylarını, mazbata'ya kendi el yazları ile 
koyduklan ve altını imzaladıkları şerhlerde belirtmişlerdir. Mazbatadaki oyların oranı 10/15 dir. Cezaların hafifletilmesi için oy kullananlar içinde en açık ve kesin ifade, eski Sadrâzamlardan Tunus'lu Hayreddin Paşanın yazısıdır. Ötekiler ise esas fikirlerini açığa vurmaktan sakınmışlar ve âdeta ağızlarında gevelemişlerdir. Bu durum karşısında Padişah, ölüm cezalarını müebbed hapse ve sürgüne çevirmekte çıkar yolu bulduğu inancına varmış görünmektedir.Böyle davranışı için ileri sürdüğü gerekçe "merhamet-i şahâne"dir.Bu gerekçe belki birkaç zavallı hakkında doğru olabilir. Fakat esasında onu böyle hareket etmeğe esevk eden asıl âmil başkadır: idam cezalarının infazı halinde memleket ve dünya kamu oyunda gösterilecek muhtemel tepkiden duyduğu korkudur. Gerçekten de memleket içinde yapılan mahkemenin iç yüzünü bilenlerin sayısı az değildir. Diğer taraftan İstanbul'daki yabancı devlet temsileileri Sultan Abdülhamid'e cezaların affi için müracaatta bulunmuş oldukları gibi İngiliz Parlâmentosunda ve genel olarak Avrupa gazetelerinde Yıldız Mahkemesi ve kararları üzerinde tartışmalar sürüp gidiyordu. Bütün bu haberler tercüme edilerek Padişaha duyuruluyordu. İşte bu şartlar altında idi ki Sultan Abdülhamid uzunca bir tereddüt devresi geçirerek Yıldız Mahkemesinin mâhud hükmünden ancak üç hafta sonra cezaları hafifletmeğe karar verdi. Bununla beraber Sultan Abdülhamid, kendi mevkïni ve hayatını korumak için vücudlarını yok etmeğe karar verdiği tehlikeli şahıŁların öldürülmelerinden vazgeçmiş değildi; bu işi sadece elverişli bir firsat çıkıncaya kadar ertelemiş bulunuyordu. Nitekim o, yukarıda sözünü ettiğimiz “Midhat Paşa ve Taif Mahkûmları" cildinde bütün ayrıntıları ile anlatılmış olduğu gibi, üç yıl kadar bir süre sonra yâni 7/8 Mayıs 1884 te, mahkûmlar içinde en tehlikeli gördügü Midhat ve Mahmut Celâleddin Paşaları, sürgün bulundukları Taif zindanında cellatlarına boğdurtmak suretiyle nihayet huzura kavuşmuştur.

İşte Uzunçarşılı üstadımız, Midhat Paşa ve zamanı konusundaki eserini ikinci cilt olarak tamamlayan Midhat Paşa ve Yıldız Mahkemesi başhıkı kitabında bu trajik olayın hikâyesini vermektedir. Kullandığı vesikalardaki deliller, vardığı hükümler hakkında her hangi bir şüpheye yer bırakmayacak kadar açı ve kesindir. Öyle görünüyor ki bu eser ile, Sultan Abdülaziz'in ölümü üzerinde öteden beri beslenen şüphe, yâni "intihar mı, katil mi?" sorunu, artık çözümlenmiş, bu konuda yıllardır devam eden tartışmalar sona ermiş ve son söz söylenmiş bulunmaktadır. Sultan Abdülaziz'in intihar ettiği, Yıldız Mahkemesinin belli bir 
takım emellerin gerçekleştirilmesi amacı ile tasnî’ edildiği sabit olmuştur ${ }^{1}$.

Eser teknik bakımından mükemmel denebilecek bir nefasette basılmış olmakla beraber içinde düzeltilmemiş veya yanlış geçmiş bâzı sözlere de rastlanmaktadır. Tertip bakımından göze çarpan cihetlerden biri, eserde kullanılmış olan çok sayıda vesikalardan bâzılarının doğrudan doğruya metin içinde, hatta çok kere özetlendikten sonra aynen ve ve bâzen metin arasında, bâzen de altnotlarda olmak üzere; bâzılarının ise metin bittikten sonra arka arkaya dizilerek verilmiş olmalarıdır. Gerek bu bakımdan, gerekse daha bâzı ayrıntılar bakımından ciltler arasında görülen ayrılıklar, ciltlerin yayınlanma tarihleri arasında mevcut bulunan uzun ylllarla izah olunabilir. Muhakkak ki eserin bütünü aynı zamanda, yazılıp yayınlanmak mümkü olsaydı bu hâl ortadan kalkar ve ciltler arasında daha sağlam bir bağlantı kurulmuş olurdu.

1) Bu vesile ile bir noktaya işaret etmek her halde yerinde olur: elimizde, bizi aynı sonuca götürecek çok önemli ve fakat şimdiye kadr ortaya konmamış başka bir vesika daha vardır. Bu da, Sultan Abdülaziz'in tahttan indirilişinden ölümüne kadar yanından hiç ayrılmamış olan ve dolayısiyle bu padişahın ölümüne yakından şahit olmuş bulunan ikinci Mâbeyincisi Fahri Beyin Hatıratıdır. Fahri Beyin kendi el yazısı ile bir nüshası elimize geçmiş olan bu Hatırat'ı, daha başka bâzı vesikalarla birlikte tarafımdan yayına hazırlanmış olup Türk Tarih Kurumunca basılmıştır. 